\title{
ACCESS SITES TO VASCULAR SYSTEM FOR ENDOVASCULAR ABDOMINAL AORTIC ANEURYSMS REPAIR
}

\author{
Petr Utikal ${ }^{\mathrm{a}}$, Martin Koecher ${ }^{\mathrm{b}}$, Petr Bachleda ${ }^{\mathrm{a}}$, Jirina Koutna ${ }^{c}$, Petr Drac ${ }^{\mathrm{a}}$, Marie Cerna ${ }^{\mathrm{b}}$ \\ a $2^{\text {nd }}$ Clinic of Surgery, University Hospital Olomouc, Czech Republic \\ Clinic of Radiology, University Hospital Olomouc \\ Clinic of Anestesiology, University Hospital Olomouc \\ e-mail:petr.utikal@fnol.cz
}

Received: April 20, 2006; Accepted: May 28, 2006

Key words: Aorta/Aneurysm/Repair/Endovascular/Access sites/Surgical/Alternative/Percutaneous/Adjunctive procedures

The authors describe their experience with access sites for endovascular abdominal aortic aneurysm repair in a group of 165 patients treated over a 10-year period.

\section{INTRODUCTION}

The ability to reliably gain access to the vascular system is fundamental to the performance of all endovascular procedures, especially those related to endovascular abdominal aortic aneurysm repair (EVAR) ${ }^{1}$. At present EVAR mostly requires open surgical access owing to the large diameter of the introducing device. Incision of the common femoral artery (CFA) surgically exposed in the groin is the most widely used access site for EVAR ${ }^{2-4}$. Narrow, stenotic and tortuous femoral or iliac arteries are responsible for EVAR access problems. They may lead to introducing device fracture or jamming and its subsequent withdrawal may lead to iliac artery damage/rupture ${ }^{5-6}$. A standard access procedure is thus not possible at all or unsuccessful with high risk of technical complications and primary treatment failure ${ }^{1,7}$. In order to overcome some of these access problems, various additional maneuvers can and should be used to facilitate or improve the access ${ }^{8-13}$. Procedures performed for EVAR access creation and its closure and access related complications in our group of patients are evaluated in this presentation.

\section{METHOD}

\section{Access creation}

\section{Standard access procedure}

One or both CFA (according to stentgraft configuration) are surgically exposed in the groin by vertical or oblique skin incision. A 7-8F sheath for angiography catheter and guidewire are first introduced via a CFA anterior wall puncture and subsequently through an arteriotomy (transverse, V-type and vertical) and iliac arteries (IA) the introducing device with the stentgraft is inserted in the aorta using a stiff wire ${ }^{1,10,14}$ (Fig. 1).

\section{Additional maneuvers}

Additional maneuvers performed intraoperatively for gaining access to the aneurysm are classified as planned and unplanned procedures. Planned procedures are part of a preformulated operative strategy. Unplanned procedures are necessary for the management of unintended complications ${ }^{10,13}$.

\section{Endarterectomy}

Direct surgical endarterectomy is performed for common femoral artery (CFA) and iliac-femoral border atherosclerotic (AS) stenotic access problems. The management of these problems in the external iliac artery (EIA) or in the common iliac artery (CIA) consists primarily of baloon dilatation (PTA), usually with stent employment. Indirect endarterectomy using a Fogarty wire catheter (modified Vollmar desobliteration) may be applied as the next step.

\section{Bimanual introduction}

It is possible to hold the iliac artery with the whole hand retroperitoneally after the inguinal ligament lifting (ligament incision is mostly necessary) and the introducing device can be inserted by force under the digital-manual EIA control in case of a stenotic and rigid artery.

\section{Pull-down maneuver (digital stretching).}

The maneuver involves the dissection of the CFA and EIA, lifting of the inguinal ligament, and using blunt dissection to reach the iliac bifurcation from the groin. When the arteries are free, a gentle pull on the artery allows the extensive tortuous artery to straighten, thus enabling the introduction of the stentgraft ${ }^{9}$ (Fig. 2). EIA surgical shortening via retroperitoenal approach is another option ${ }^{15}$. 

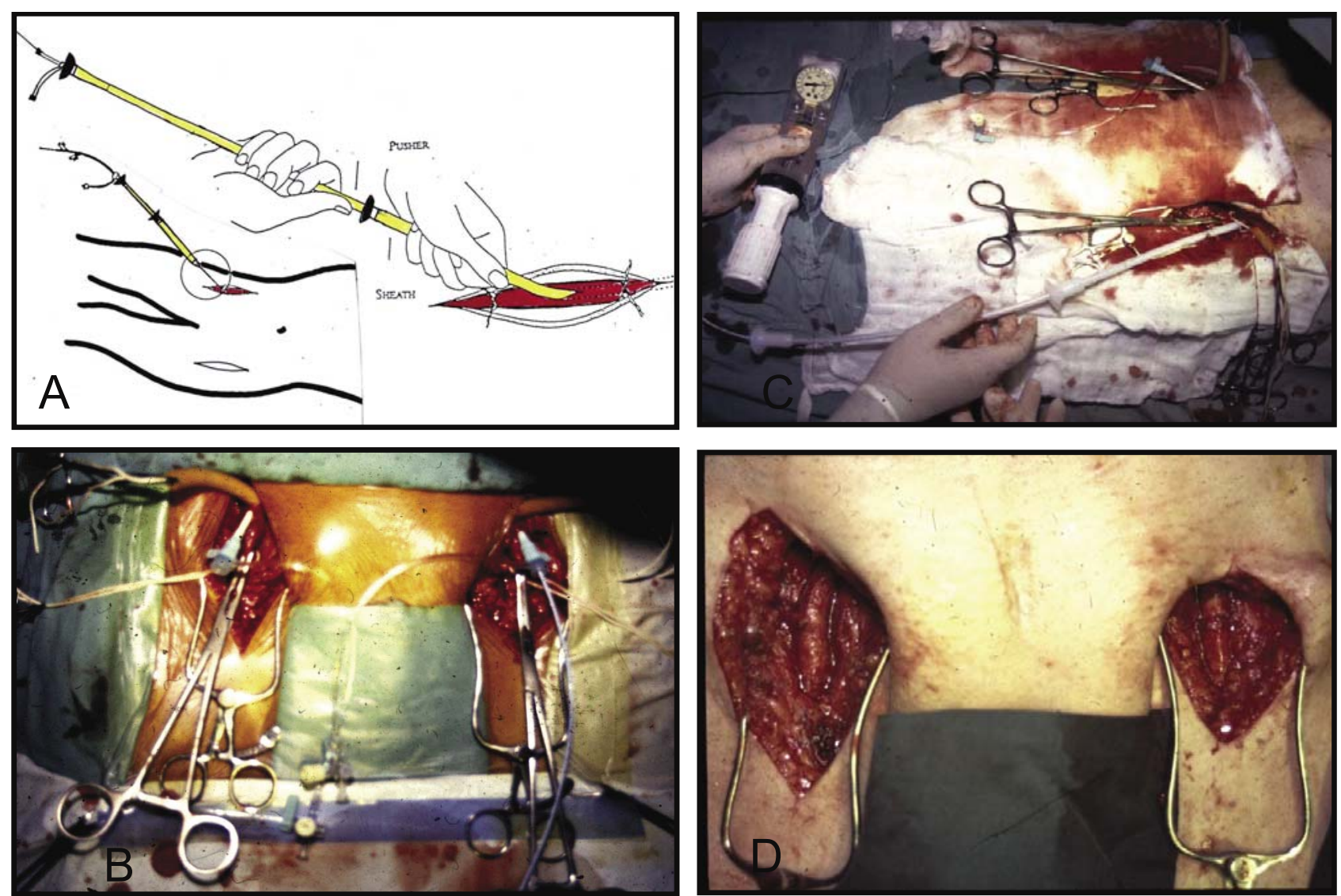

Fig. 1. Classical vascular access for EVAR.

A: Drawing of the initial part: stentgraft system introduction.

B: Peroperative view. Surgically prepared access (groin incisions) to CFA (with sheaths in arteriotomies) on both sides.

C: Peroperative view. Stentgraft system introduced through the CFA arteriotomy on the left.

D: Peroperative view. The EVAR procedure is finished, CFA arteriotomies are closed by direct suture.

Table 1. EVAR access sites $(\mathrm{n}=312)$

\begin{tabular}{|lcclrr|}
\hline Common femoral artery & 300 & $96 \%$ & $\begin{array}{l}\text { surgically } \\
\text { percutaneously }\end{array}$ & $\begin{array}{r}286 \\
14\end{array}$ & $\begin{array}{r}95.3 \% \\
4.7 \%\end{array}$ \\
\hline Iliac-femoral bypass & 12 & $4 \%$ & & & \\
\hline
\end{tabular}

Table 2. EVAR access sites $(n=312)$.

Iliac arteries tortuosity and occlusions solution $(n=5417.2 \%)$

\begin{tabular}{|l|c|c|}
\hline Baloon dilatation, stent & 16 & $5.1 \%$ \\
\hline Surgical indirect endarterectomy & 7 & $2.2 \%$ \\
\hline Bimanual introducing & 14 & $4.5 \%$ \\
\hline Pull down maneuver & 5 & $1.6 \%$ \\
\hline Iliac-femoral bypass & 12 & $3.8 \%$ \\
\hline
\end{tabular}



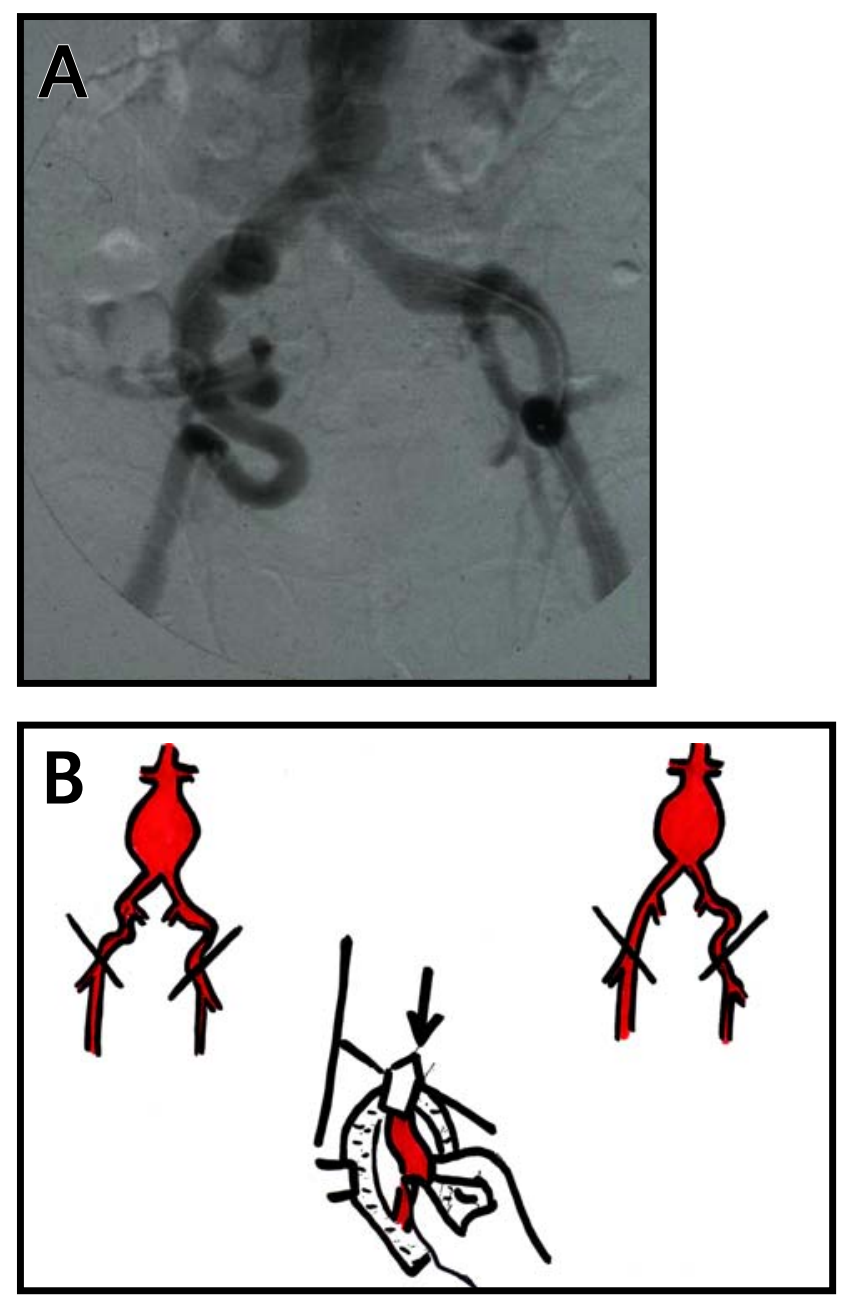

Fig. 2. Pull down maneuver.

A: DSA shows too tortuous EIA on the right side

B: Drawing of straightening EIA by pull

C: Peroperative view of too tortuous EIA from the groin access

\section{Alternative access}

The alternative approach refers to vascular access created above the inguinal ligament in case the CFA or/ and EIA are too unfavourable to permit safe device insertion. The stentgraft can be introduced directly, or more typically, via a vascular prosthesis sutured end to side of the CIA or aorta retroperitoneally exposed via a lower quadrant abdominal pararectal incision (Fig. 3, 4). The prosthesis is used either as a temporary conduit (dacron tube prosthesis of adequate diameter to the stentgraft introducer) for the introduction itself or it is subsequently left in place as an iliac/aorto-femoral homolateral or crossover bypass (ePTFE prosthesis), thus solving not only access to the aneurysm but also the AS stenoses in the iliac arteries ${ }^{8,11-12}$.

\section{Access closure}

Primary closure with 5.0 monofilament sutures (running or interrupted) in case of severe AS- free CFA is possible.

Sometimes CFA is so diseased and/or damaged after the introduction that a CFA endarterectomy with patch

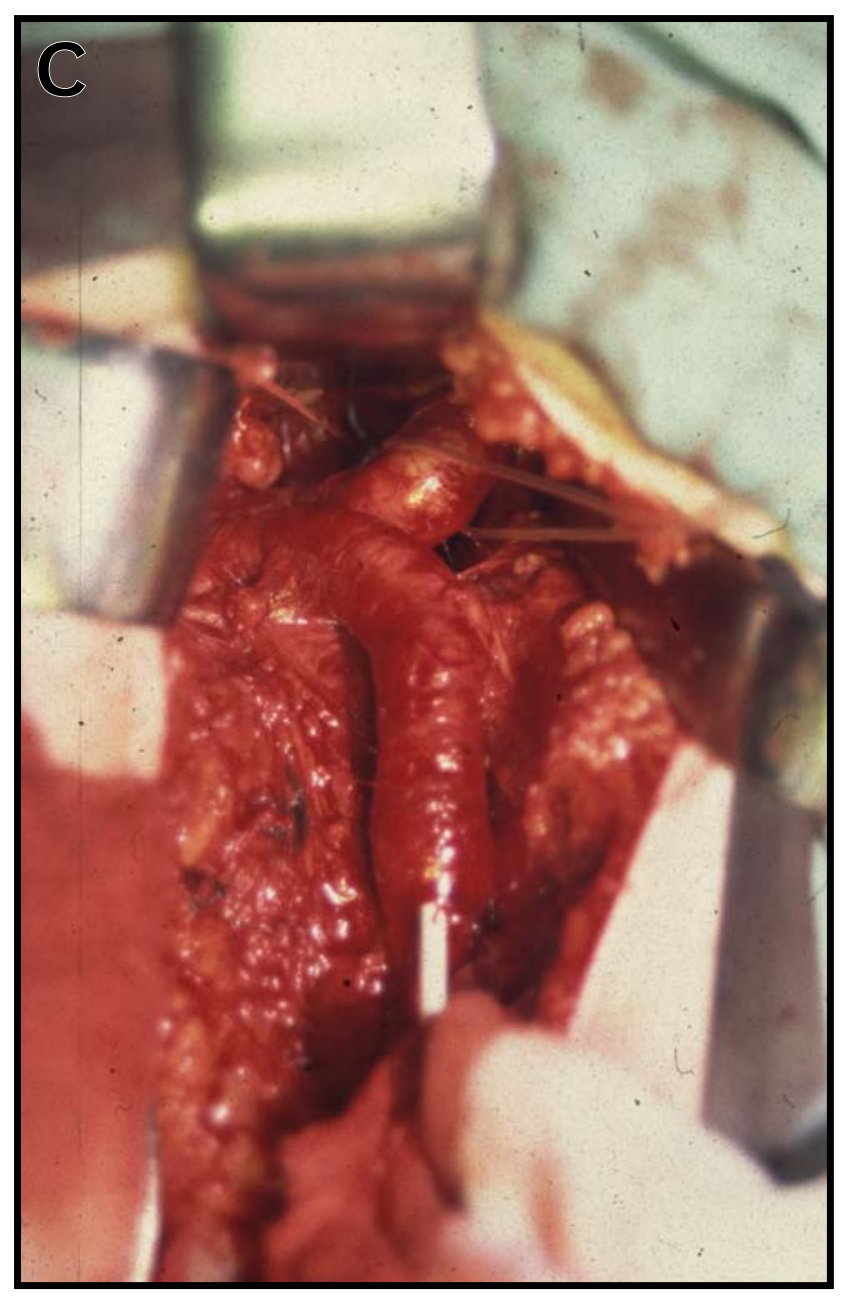

plastic or even its excision and short prosthesis interposition is required (Fig. 5). The inflow anastomosis of the femoral-femoral bypass in aortouniiliac stentgraft practically covers up the vascular access.

\section{Percutaneous procedure}

Complete percutaneous EVAR using CFA percutaneous suture systems is feasibile in some patients ${ }^{16-19}$ (Fig. 6).

\section{Access site complications}

Access site complications are presented as specific and non-specific. Specific complications are connected with the introducing procedure itself; CFA/IA perforation, disection which require immediate endovascular or surgical repair or even conversion to open repair. Non-specific complications are connected with the operating wound; haematoma (in groin or in retroperitoneal pelvic space), false aneurysm (especially after percutaneous procedure), lymph fistula and wound infection. These complications can be observed, spontanously solved and only occasionally do they require open surgical repair ${ }^{10,15}$. 

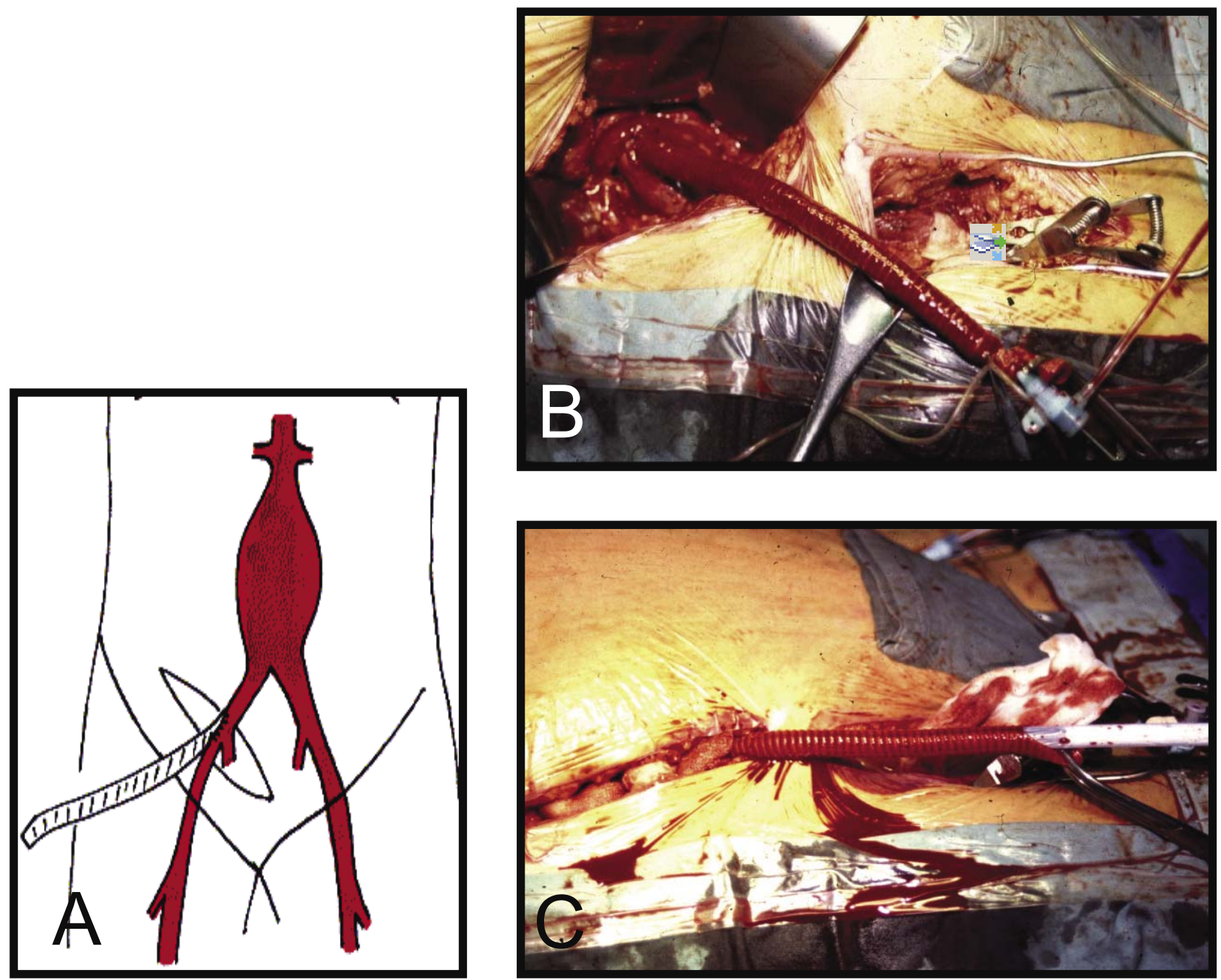

Fig. 3. Alternative access: iliac conduit.

A: Drawing of temporary iliac conduit on the CIA

B: Peroperative view. Retroperitoneally created temporary iliac conduit.

C: Peroperative view. Stentgraft introduction through the iliac conduit.
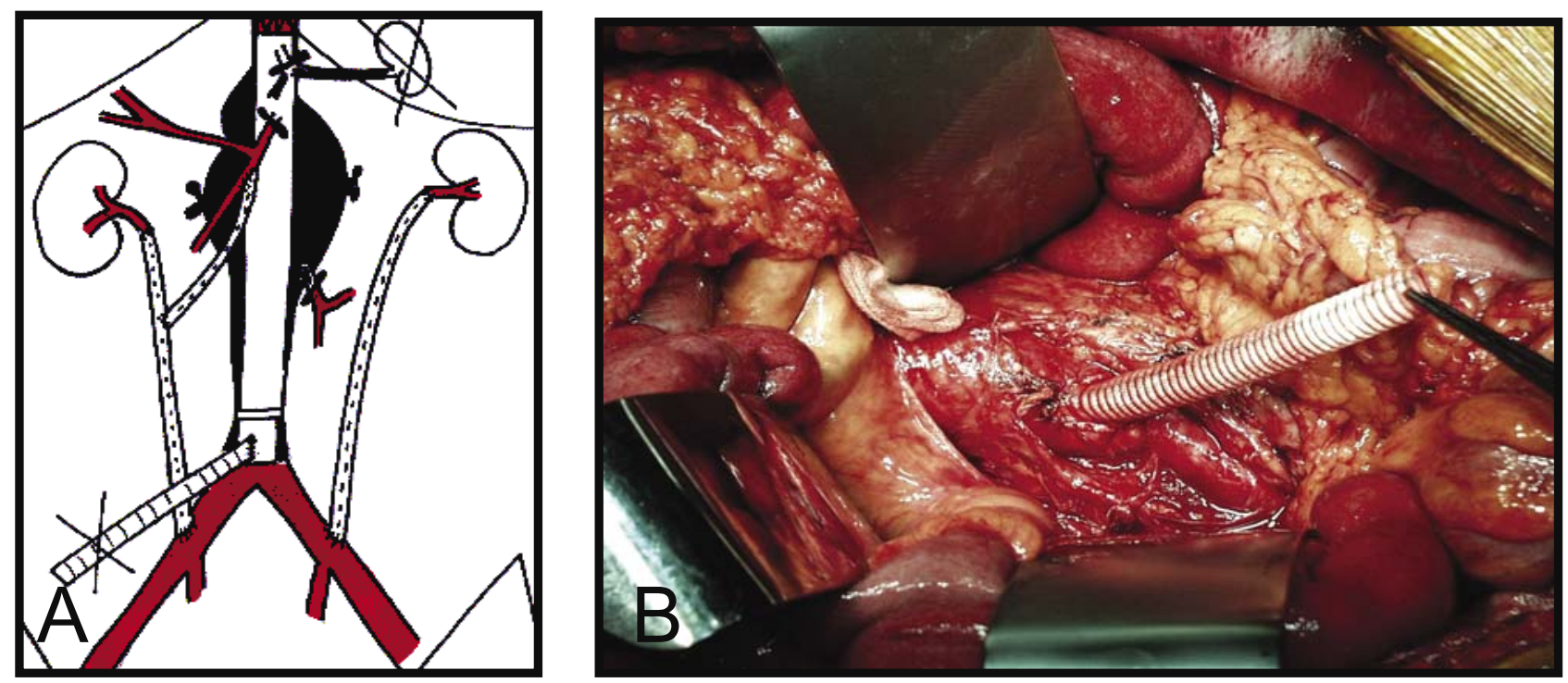

Fig. 4. Alternative access: aortic conduit.

A: Drawing of temporary aortic conduit used in case of complex the total abdominal aorta aneurysm

B: Peroperative view of the transperitonealy created temporary aortic conduit. 

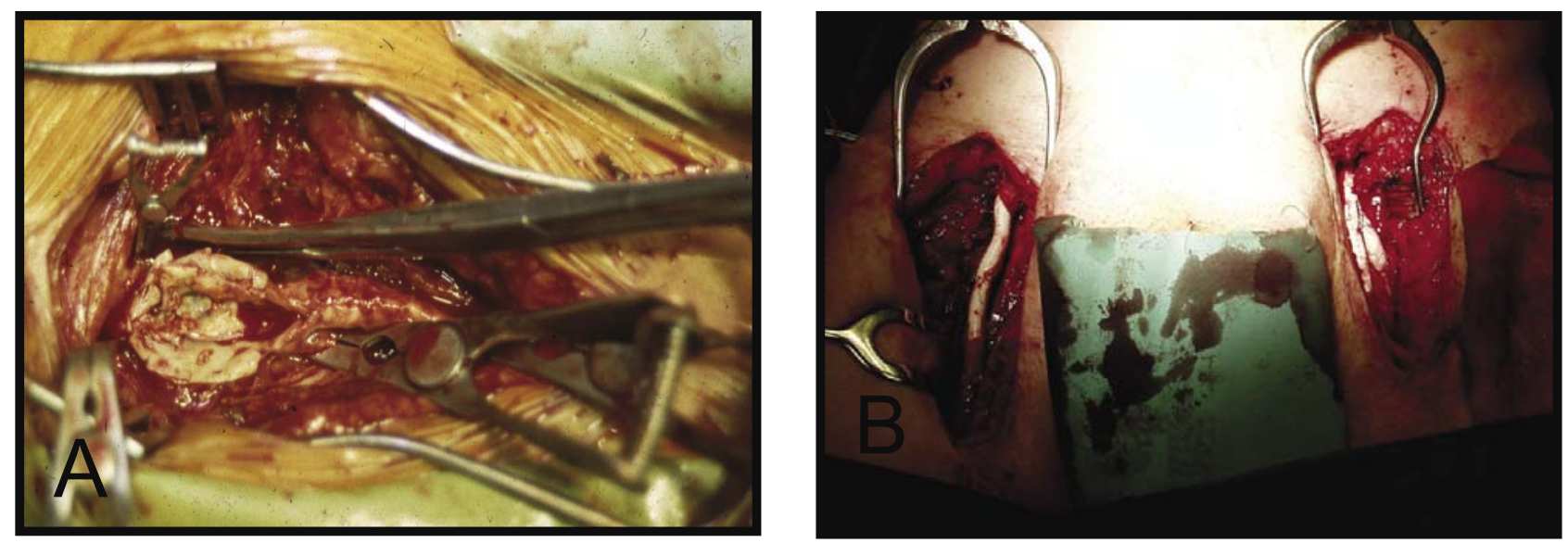

Fig. 5. Classical vascular access for EVAR.

A: AS changed CFA demaged during stentgraft introduction

B: CFA repair using ePTFE interposition
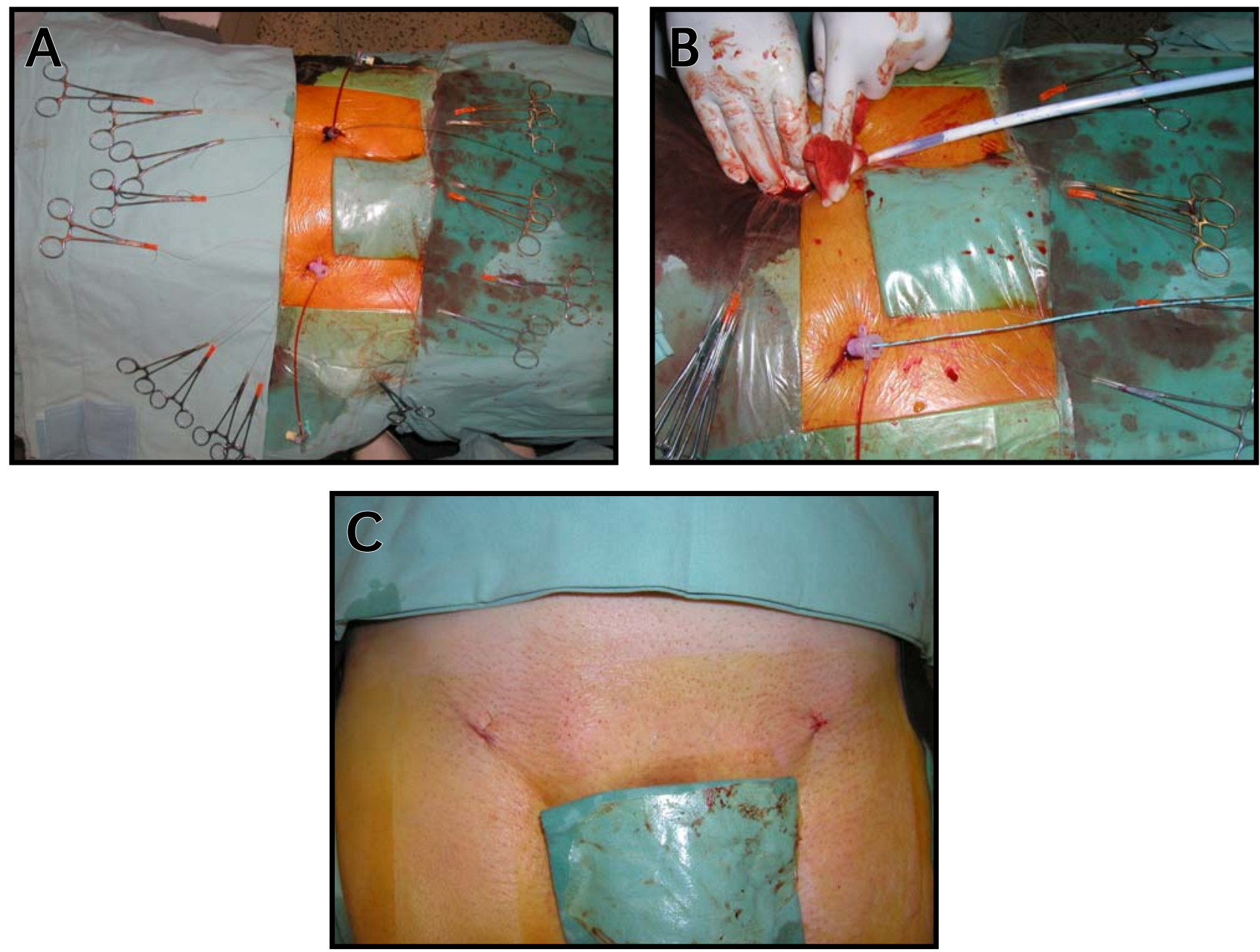

Fig. 6. Percutaneous EVAR

A: Peroperative view. Sutures of the percutaneous closure device prepared for CFA closure

B: Peroperative view. Percutaneous stentgraft introduction.

C: Peroperative view. Percutaneous access closed by single skin stich. 


\section{PATIENTS, RESULTS}

Between April 1996 and April 2005, 170 stentgrafts were introduced in 168 patients with asymptomatic AAA for standard accepted indications. One type of stentgraft system: Ella (ELLA CS, Hradec Králové, Czech Republic) was used for AAA exclusion in all patients. Stentgraft configuration included 3 aortic tubes, 142 bifurcated (bimodular) grafts, and 25 aortouniiliac grafts ${ }^{20-22}$. These stentgrafts required a total of 312 vascular accesses. All the stentgraft introducing devices were successfully inserted and there was no failed vascular access related conversion to open surgery in our patients. CFA $(\mathrm{n}=300)$ was used in $96 \%$ of accesses. Standard access procedure $(n=286)$ was used in $95.3 \%$. CFA was exposed by vertical incision in all patients and two types of CFA arteriotomies were used; transverse $(\mathrm{n}=65 ; 22.7 \%)$ and vertical $(\mathrm{n}=221$; $77.3 \%)$. Percutanous access $(n=14)$ was used in $4.7 \%$. In 8 patients the whole bifurcated stentgraft $(n=6)$ or the contralateral limb of the bifurcated stentgraft $(n=2)$ were percutaneously introduced. Ilio-femoral bypass $(n=12)$ was used in $4 \%$ of the accesses (Table 1). Patients with temporary aortic conduits $(n=3)$ created for the implantation of an aortic tube stentgraft in cases of thoracic aorta aneurysm $(\mathrm{n}=1)$ and type IV thoracoabdominal aneurysm $(n=2)$ were not statistically included in this group of patients ${ }^{11-12}$ (Fig. 4). The additional maneuvers and procedures $(n=54)$ were successfully used for iliac artery tortuosity and occlusions solution in $17.2 \%$ (Table 2). There was no increased morbidity or mortality connected with the additional retroperitoneal maneuvers. The CFA was surgically closed in $56 \%$ of accesses using direct suture, and additional surgical corrections were used in $36 \%$ of accesses (Table 3). Local access site complications occured in $29(9.4 \%)$ accesses (Table 4$)$.

There were no vascular access complications requiring open surgical conversion and no severe groin wound and lower extremity threatening complications. All of the IA traumata were immediately solved successfully. Both EIA perforations and two of the EIA dissections were surgically solved by retroperitoneal iliac-femoral bypass $(n=4)$. Stentgraft extension $(n=1)$ and indirect surgical endarterectomy $(n=2)$ were used in the other dissection cases. Most wound complications were spontaneously resolved, but early surgical haemathoma evacuation was also required $(\mathrm{n}=3)$, and subcutaneous space due to lymph fistula was resutured $(n=2)$. In cases of wound dehiscence based on wound haemathoma infection, operative revison (debridement) was required. All superficial wound infections were resolved with antibiotics only. Lower extremity ischemic complications due to periphery embolisation were not observed.

There were no complications where the retroperitoneal approach was used, and there were no problems (herniation) related to ligament incision. In percutaneously performed accesses, the 8 and 10F Prostar devices (Perclose Inc, Vascular Abott Devices, Redwood City, USA) were used for CFA closure. Success was achieved in 11 cases (79\%) with only 3 closure failures which necessitated immediate $(n=2)$ and elective $(n=1)$ conversion to open groin incision and surgical CFA suture ${ }^{19}$.

Table 3. EVAR access site $(n=312)$. CFA primary surgical closure $(n=286)$.

\begin{tabular}{|l|l|r|}
\hline Uncomplicated & $\mathbf{1 8 3}$ & $\mathbf{6 4} \%$ \\
suture direct & 160 & $56 \%$ \\
covered up in FF bypass anastomosis & 23 & $8 \%$ \\
\hline Complicated & $\mathbf{1 0 3}$ & $\mathbf{3 6 \%}$ \\
ePTFE patch & 49 & $17 \%$ \\
endarterectomy + patch & 18 & $6.4 \%$ \\
CFA excision + ePTFE interposition & 36 & $12.6 \%$ \\
\hline
\end{tabular}

Table 4. EVAR access site $(n=312)$. Local complications $(n=29,9.4 \%)$

\begin{tabular}{|l|r|c|}
\hline $\begin{array}{r}\text { Vascular } \quad \text { perforation } \\
\text { iliac artery trauma dissection }\end{array}$ & $\mathbf{7}$ & $\mathbf{2 . 3} \%$ \\
\hline Groin wound & 2 & \\
hematoma & $\mathbf{2 2}$ & $\mathbf{7 . 1} \%$ \\
seroma/lymph fistula & 9 & \\
dehiscence & 4 & \\
infection & 3 & \\
false aneurysm in failed percutaneous CFA suture & 6 & \\
\hline
\end{tabular}




\section{DISCUSSION, CONCLUSION}

Vascular access for EVAR depends on vascular access site (CFA and IA) anatomy and pathology for the first and on introducing device diameters corresponding with the stentgraft configuration based on AAA morphology for the second.

Thorough anatomical evaluation of the AAA as well as of the access arteries is crucial to ascertain patient suitability for EVAR and to avoid access failure ${ }^{6,23}$. Because of the large diameter of the current aortic stentgraft introducing devices, a surgicaly created controlled entry into the artery lumen is mostly necessary to avoid access complications. All incisions in the groin region, especially in obese patients, have a high risk of wound infection or lymph leak complications, with a lower rate reported in oblique type of incisions. We preferred classical vertical incision for CFA exposure with acceptable local wound complications rate. The transverse or V-type of arteriotomy is only possible in large or soft and AS-free CFA. The V-type incision has the advantage of providing a "ramp" on which the introducing device slides.

In CFA significantly diseased by atherosclerosis, verical arteriotomy is mandatory. This allows for a better examination of the lumen and for careful arteriotomy closure ${ }^{1}$. We preferred vertical arteriotomy and the transverse one was mostly for the contralateral bifurcated stentgraft limb ( $16 \mathrm{~F}$ devices). From the access sites point of view, the current EVAR morphological indication criteria include significant stenosis and tortuosity- free IA of diameter no less than $8 \mathrm{~mm}$ or $6-8 \mathrm{~mm}$ without calcifications at least on one side ${ }^{1,5-7}$. The dimensions of the introducing device, i.e. its diameter, depend on the construction, type and size (length and diameter) of the stentgraft. Current technologies of stentgraft construction do not allow the use of introducing devices with an outer diameter lower than $18-24 \mathrm{~F}$ for the body of the bifurcated stentgraft and $16-18 \mathrm{~F}$ for the iliac segments ${ }^{23}$. When using introducing devices of a smaller diameter than that corresponding with that required by the stentgraft, there is a danger of stentgraft deformation (shortening) during its extension. The preferred type of AAA exclusion - bifurcated stentgraft - requires an iliac artery without the presence of significant stenoses and tortuosity on either side. In case of bimodular bifurcated stentgraft, the side of components introduction is selected so that the artery diameter corresponds with that of the introducing device.

For stentgraft body introduction, we select the side with an artery with a larger and direct diameter and less AS changes and calcifications. The introduction of the contralateral iliac limb is mostly problem-free ${ }^{3-4}$. In case of unilateral CFA and IA access pathology, the use of aortouniiliac stentgraft introduced from the opposite side can be the best solution ${ }^{24}$.

The introducing device is of extensively large diameter (24F and more) in case of unibody bifurcated stentgraft configuration or in case when a stentgraft of a high length and large diameter (according to AAA) is needed and therefore alternative access is mostly required. Smaller- diameter introducing devices with a connical top can overcome the problem of narrow IA, but tortuosity remains a problem in providing access through these arteries.

The use of extra-stiff guidewire (from left brachial artery to the preferred femoral artery ) is the basic method to extend the artery in case of tortuosity, and when no heavy circumferential calcification is present, the IA is capable of considerable mobility. All the additional maneuvers were successful when used in our patients. When the additional maneuvers are not primarily possible or if they have failed, an alternative access is necessary. Iliac-femoral bypass for access is the most frequent of the additional vascular surgical procedures performed in $\mathrm{EVAR}^{13}$. All the retroperitoneal alternative accesses are connected with a slightly higher invasivity and, in case of the prosthesis use, with a higher blood loss in filling the prosthesis in contrast to classical transfemoral access, but hemodynamically is the less stressful procedure and it remains acceptable. We also created a bilateral iliac-femoral bypass for bifurcated stentgraft insertion when necessary $(n=2)$. We generally used a 22-24F introducing device for the main body of the bifurcated stentgraft and $16-18 \mathrm{~F}$ for the contralateral limb. It is true that these diameters also depend on the type of stentgtraft system used.

We used the Ella stentgrafts, which are of rugged construction and are loaded into the large diameter introducing device, which resulted in the use of alternative access in the more problematic access cases. On the other hand, the Ella introducing device is sufficiently flexible and facilitates reliable introduction. We can confirm this based on the results with $66 \%$ tortuous and $32 \%$ stenosed IA access sites in our group of patients. The advantage of the rugged Ella stentgrafts design is the stentgraft stability and this is reflected in the long-term results ${ }^{20-22,25}$. The method of CFA arteriotomy surgical closure corresponds with the type of incision and AS changes (stenosis/aneurysm) of this site ${ }^{1}$. In our group of patients the transverse arteriotomy was closed using direct suture in $69 \%$ and the vertical one in $52 \% .98 \%$ of the complicated accesss closures were performed in AS stenoses, with CFA AS aneurysms accounting for $2 \%$, and the closures were mostly on the side of the bifurcated stentgraft body and/or when an introducing device with a diameter of 22-24 $\mathrm{F}$ was used. The rate of vascular access complications increases with narrow iliac artery diameter or large introducing system diameter ${ }^{26}$. Iliac artery diameters below $7 \mathrm{~mm}$ are associated with an increased incidence of complications ${ }^{27}$. Unfortunately, iliac artery rupture diagnosis is mostly imposssible before the introducing system withdrawal, and subsequent endovascular solution using stentgraft insertion is problematic ${ }^{28}$. Surgical repair with prosthesis interposition therefore seems to be the best option, as it was in our two cases of EIA trauma. Access failure is becoming the most common cause of primary conversion to open surgical repair ${ }^{29}$. All endovascular and surgical procedures have to be attempted to overcome the access problems before the decision for conversion to open surgery is made. To reduce the risk of access complications in case of too tortuous or stenotic iliac arteries (especially 
in the presence of circumferential calcifications) and/or in need of the large diameter introducing devices with repetitive forceful introduction, the alternative access as an easier, safer and more feasible vascular access option is primarily indicated with greater likelihood of success ${ }^{30}$. In our patients, iliac-femoral bypasss was used as a primary planned alternative access, and in three patients with EIA rupture it was used as unplanned. The $24 \mathrm{~F}$ introducing device was used in each case when the iliac-femoral bypass was required. Although open surgical access is the most common successful procedure for EVAR, there is a tendency to perform it completely percunateously because this is the least invasive technique ${ }^{1}$. The condition for complete percutaneous procedure without access artery suture, $12 \mathrm{~F}$ introducing-delivery device diameter, is impossible given the current state of stentgraft construction. Therefore, the artery closure problem was solved by percutaneous artery suture devolopment. However, current percutanous suture devices, especially in obese patients with scarred groins and calcificated iliac arteries, are not safely feasible and percutaneous EVAR still often remains unreliable ${ }^{16-18}$. All our percutanous closure failures were in obese patients (false femoral aneurysm developed in one) and calcified $\mathrm{CFA}^{19}$. In current situation, it seems more effective to only use the percutaneous access for the introduction of the contralateral limb of the bifurcated stentgraft. Extreme morphological EVAR (less stringent anatomical criteria) indication may be used in eldery, high risk patients with large AAA. Open surgical access facilitates better and more rapid recognition and solution of problems when they occur. Under these circumstances, the risk of the procedure is acceptable. EVAR rejection or primary surgical conversion due to failed standard access procedure is thus less common and is the last option. New technological developement may lead to new, more flexible stentgraft designs with reducing the required diameter of the introducing systems. This will be a remarkable progress towards non-limited EVAR, especially in terms of the percutaneous one, in the future and towards reduced incidence of access limitations and complications.

\section{REFERENCES}

1. Hodgson KJ, Mattos MA, Summer DS. (1997) Access to the vascular system for endovascular procedures: Techniques and indications for percutaneous and open arteriotomy approaches. Semin Vasc Surg 10, 206-221.

2. Parodi JC, Palmaz JC, Barone HD. (1991) Transfemoral intraluminal graft implantation for abdominal aortic aneurysms. Ann Vasc Surg 5, 491-499.

3. Chutter TAM, Green RM, Ouriel K, Fiore WM, DeWiese JA (1993) Transfemoral endovascular aortic placement. J Vasc Surg 8, 185-195.

4. Chuter TAM, Wendt G, Hopkinson BR, Scott RAP, Risberg B, Walker P J, White G. (1995) Transfemoral insertion of a bifurcated endovascular graft for aortic aneurysm repair: the first 22 patients. Cardiovasc Surg 3, 121-128.

5. Carpenter JP, Baum RA, Barker CF. (2001) Impact of exclusion criteria on patient selection for endovascular abdominal aortic aneurysm reparir. J Vasc Surg 34, 1050-1054
6. May J, White GH, Yu W, Waugh RC, Stephen MS. Harris JP. (1996) Results of endoluminal grafting of abdominal aortic aneurysms are dependent on aneurysm morphology. Ann Vasc Surg 10, 254-261.

7. Ahn SS, Rutherford RB,Johnston KW, May J, Veith FJ, Baker JD, Ernst CB, Moore WS. for the Ad Hoc Committee for Stadardized Reporting Practices in Vascular Surgery of The Society for Vascular Surgery/International Society for Cardiovascular Surgery. (1997) Reporting standards for endovascular abdominal aortic aneurysm repair. J Vasc Surg 25, 405-410.

8. May J, White GH, YuW, Waugh R, Harris JP. (1994) Treatment of complex abdominal aortic aneurysms by a combination of endoluminal and extraluminal aortofemoral grafts. J Vasc Surg 19, 924-933.

9. Parodi JC, Schüonholz CJ. Stent-graft combination: a new technique for the treatment of aneurysms. In: Parodi JC, Veith FJ, Marin ML. (1999) Endovascular grafting techniques. Williams and Wilkins, Baltimore, 57-64.

10. Chaikoff EL, Blankenstein JD, Harris PL, White GH, Zarins ChK, Bernhard VM, Matsumura JS, May J, Veith FJ, Fillinger MF, Rutherford RB, Kent KG, for the Ad Hoc Committee for Standardized Reporting Practices in Vascular Surgery of the Society for Vascular Surgery/American Association for Vascular Surgery. (2002) Reporting standards for endovascular aortic aneurysm repair. J Vasc Surg, 35, 1048-1060.

11. Utíkal P, Köcher M, Bachleda P, Dráč $\mathrm{P}$, Buriánková E, Kojecký Z, Ürge J. (2001) Léčba AAA na přelomu tisíciletí - stentgrafting - role cévního chirurga. Prakt Flebol 10,111-113.

12. Utíkal P, Köcher M, Koutná J, Bachleda P, Dráč $P$, Černá M, Buriánková E, Herman J. (2005) Combined strategy in AAA elective treatment. Biomed Pap Med Fac Univ Palacky Olomouc 149, 159-163.

13. Hobo R, vanMarrewijk CJ, Leurs LJ, Laheij RJF, Buth J on behalf of the EUROSTAR collaborators. (2005) Adjuvant procedures performed during endovascular repair of abdominal aortic aneurysm. Does it influence outcome? Eur J vasc Endovasc Surg 30, 20-28.

14. Stoney RJ, Effeney DJ. (1998) Comprehensive vascular exposures. Philadelphia, PA: Lippincott-Raven, 8-25.

15. Liewald F, Scharrer-Pamler R, Görich J, Kapfer X, Seifarth H, Halter G, Sunder-Plassman L. (2001) Problems with endovascular therapy of aneurysms. Eur J Vasc Endovasc Surg 22, 251-256.

16. Traul DK, Clair DG, Gray B, O'Hara PJ, Ouriel K. (2000) Percutaneous endovascular repair of infrarenal abdominal aortic aneurysms: a feasibility study. J Vasc Surg 32, 770-776.

17. Howell M, Villarel R, Krajcer Z. (2001) Percutaneous access and closure of femoral artery access sites associated with endoluminal repair of abdominal aortic aneurysms. J Endovas Ther 8, 68-74.

18. Teh LG, Sieunarine K, van Schie G, Goodman MA, LawrenceBrown M, Prendergast FJ, Hartley D. (2001) Use of the percutaneous vascular surgery device for closure of femoral access sites during endovascular aneurysm repair:lessons from our experience. Eur J Vasc Endovasc Surg 22, 418-423.

19. Černá M, Köcher M, Bư̌val S, Šišola I, Utíkal P, Bachleda P, Dráč P. (2004) Perkutánní šicí zařízení Closer, naše zkušenosti. Čes Radiol 58,125-130.

20. Utíkal P, Köcher M, Bachleda P, Novotný J, Ürge J, Dráč P. (2000) Tř́leté zkušenosti stentgraftingem AAA ve FN UP v Olomouci. Prakt Flebol 9,175-179.

21. Köcher M, Utíkal P, Buriánková E, Koutná J, Bachleda P, | Novotný J, Heřman M, Benýšek V, Bučil J, Černá M. (2001) Čtyřleté zkušenosti se stentgraftem ELLA v endovaskulární léčbě AAA. Čes Radiol 55, 159-166.

22. Köcher M, Utíkal P, Koutná J, Bachleda P, Buriánková E, Heřman M, Bučil J, Benýšek V, Černá M, Kojecký Z. (2004) Endovascular treatment of abdominal aortic aneurysms-6 years of experience with Ella stent-graft system. Eur J of Radiol 51, 181-188.

23. Schumacher H, Eckstein HH, Allenberg JR. (1999) Gefässendoprothetik: Entwiklung, aktueller Stand und Perspektive einer neuen Technologie. Chirurg 70, 858-867.

24. Yusuf SW, Baker DM, Hind RE, Chuter TAM, Whitaker SC, Wenham PW, Gregson RHS, Hopkinson BR. (1995) Endoluminal 
transfemoral abdominal aortic aneurysm repair with aorto-uniiliac graft and femorofemoral by pass. Br J Surg 82, 916-920.

25. Köcher M, Utíkal P, Sekanina Z, Bachleda P, Novotný J. (1998) Léčba AAA bifurkačními stentgrafty Ella - první zkušenosti. Rozhl Chir 77, 260-266.

26. White G H, May J, Petrasek P. (2000) Specific complications of endovascular aortic repair. Semin Intervent Cardiol 5, 35-46

27. Naslund TC, Edwards WH, Neuzil DF. (1997) Technical complications of endovascular abdominal aneurysm repair. J Vasc Surg 26, 502-509.
28. Murphy KD, Richter GM, Henry M. (1996) Aortiliac aneurysms: management with endovascular stent-graft placement. Radiology 198, 473-480.

29. Cuypers PW, Laheij RJ, Buth J. (2000) Which factors increase the risk of conversin to open surgery following endovascular abdominal aortic aneurysm repair? The EUROSTAR collaborators. Eur J Vasc Endovasc Surg 20, 183-189.

30. Verzini F, Cao P, De Rango P, Parlani G, Xanthopoulos D, Iacono G, Panuccio G. (2006) Conversion to open repair after endografting for abdominal aortic aneurysm: causes, incidence and results. Eur J Vasc Endovasc Surg 31, 136-142. 